\title{
Ethik ja - aber bitte ohne Belehrung!
}

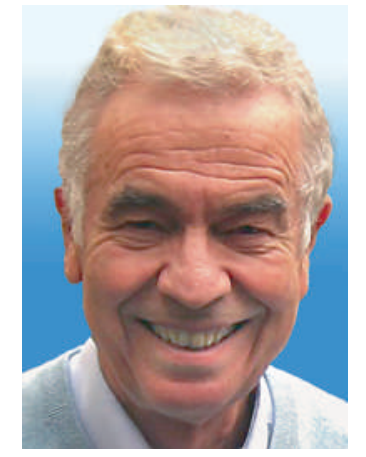

Hans Stalder
* Prof. Dr. med. Hans Stalder, Facharzt FMH für Innere Medizin FMH, Redaktionsmitglied, ist ehemaliger Direktor der Policlinique de Médecine und des Départements de Médecine communautaire des Hôpitaux Universitaires de Genève.
In der SÄZ vom 14. März dieses Jahres [1] kritisiert die Zentrale Ethikkommission (ZEK) der Schweizerischen Akademie der Medizinischen Wissenschaften (SAMW) gewisse, vereinzelte Fälle von «nicht vertretbarer Praxis der ärztlichen Suizidhilfe» und führt die Umstände an, unter denen der Arzt befugt wäre, diese Hilfe zu leisten. Basierend auf ihrer Richtlinie aus dem Jahr 2004 [2] unterstreicht die ZEK u. a., dass Freitodbegleitung nur für Patienten praktiziert werden darf, deren Lebensende nahe ist. Als ob sie bei dieser Stellungnahme doch nicht ganz so sicher wäre, ergänzt sie, dass «eine grundsätzliche Diskussion über diese umstrittene Frage unerlässlich ist». In der Tagespresse [3, 4] geht der Vizepräsident der ZEK noch weiter. Er kritisiert ebenfalls Vorkommnisse, in denen die Ethikregeln des Standes verletzt worden seien, vor allem den von einer Allgemeinmedizinerin in der SÄZ beschriebenen Fall [5] der ihm «die Haare zu Berge stehen liess» ... [4].

Diese Stellungnahmen bedürfen einiger Kommentare:

1. Sofern keine egoistischen Beweggründe vorliegen, ist die Suizidhilfe in der Schweiz nicht strafbar. In ihrer Richtlinie [2] bemerkt die ZEK zu Recht, dass «dieses Prinzip für alle Menschen gilt», somit auch für den Arzt. Warum also sollte er anders behandelt werden als der Rest der Bevölkerung? Die SAMW stellt fest und bedauert es, dass der begleitete Suizid immer mehr zu einer medizinischen Angelegenheit wird, was ja in dem vor nahezu einem Jahrhundert verfassten Art. 115 StGB durchaus nicht vorgesehen war. Somit ist es wichtig, dass sich die Ärzte in diesem Bereich an entsprechende Richtlinien halten können. Da nur der Arzt ein letales Medikament verschreiben darf, verfügt er über humanere Mittel als der Laie mit dem Plastiksack. Daher auch der Erfolg von Organisationen wie EXIT. Sich in einem so delikaten Moment seines Lebens an externe «Spezialisten» wie EXIT wenden zu müssen, ist jedoch kaum zufriedenstellend. Es stellt sich daher die Frage, ob die ZEK den behandelnden Arzt nicht vielmehr unterstützen als ihn kritisieren sollte. Dieser kennt den Patienten ja am besten und sollte mit ihm nicht nur über seinen Sterbewunsch sprechen, sondern ihm - sollte sich das Verlangen nach Freitodbegleitung als dauerhaft erweisen und wiederholt, bei voller Urteilsfähigkeit, zum Ausdruck gebracht werden Alternativen aufzeigen oder eben selbst bereit und in der Lage sein, diesen letzten ärztlichen Eingriff zu vollziehen.
2. Die Richtlinie der SAMW [2] stammt aus dem Jahr 2004 und ist überholt. In letzter Zeit wurde das Thema Sterben in der Bevölkerung heftig diskutiert, und es gab Abstimmungen mit grosser Mehrheit zugunsten der Sterbehilfe. Die Richtlinie lässt beispielsweise die Freitodbegleitung nur zu, wenn der nahe Tod bevorsteht. Ohne an dieser Stelle auf das äusserst sensible Thema der Suizidhilfe bei psychisch Kranken oder «Lebensmüden» eingehen zu wollen (selbst wenn eine Hilfe in diesen Fällen in der Schweiz nicht strafbar ist), gibt es genügend Zeugnisse von unzumutbarem Leiden, das durch unheilbare, jedoch nicht unmittelbar tödlich verlaufende Krankheit bedingt ist. Auch der Abschnitt über Suizidbeihilfe in Pflegeheimen muss nach der Volksabstimmung im Kanton Waadt revidiert werden.

3. Und schliesslich: Ne sutor ultra crepidam! Es ist nicht Aufgabe einer Ethikkommission, die Ärzte moralisch zu belehren und sie ins Gebet zu nehmen! In den fundamentalen Fragen von Leben und Tod darf jeder seine eigenen Überzeugungen hegen. Wenn jedoch ein katholischer Theologe in seiner Funktion als Vizepräsident der ZEK bestimmte Ärzte tadelt und sagt, «die einzig sinnvolle Reglementierung bestünde darin, die Suizidhilfe zu untersagen» [4], läuft er damit Gefahr, den guten Ruf der SAMW zu untergraben. Es obliegt nicht der ZEK, sondern den Standeskommissionen der kantonalen medizinischen Fachgesellschaften, zu intervenieren, wenn Kollegen die Standesethik nicht respektieren, und der Justiz, wenn Ärzte gegen das Gesetz verstossen. Nebenbei darf nicht vergessen werden, dass der begleitete Freitod immer ein unnatürlicher Tod ist und eine Intervention der Polizei und der Justiz nach sich zieht.

Hans Stalder *

\section{Literatur}

1 Probleme bei der Durchführung von ärztlicher Suizidhilfe. Stellungnahme der Zentralen Ethikkommission (ZEK) der SAMW. Schweiz Ärztezeitung. 2012;93(11):411-2.

2 Betreuung von Patientinnen und Patienten am Lebensende. Medizinisch-ethische Richtlinien der SAMW. 2004.

3 Kritik an Suizidhilfe durch Ärzte. Neue Zürcher Zeitung. 16.3.2012.

4 Pas au médecin d'aider à mourir. La Liberté, 27.3.2012.

5 Preisig E. Palliativmedizin und Freitodbegleitung: Erfahrungsbericht einer Hausärztin. Schweiz Ärztezeitung. 2011;92(41):1588-9. 